\section{State of the Art Review}

\section{Check for updates}

\section{OPEN ACCESS}

Received: May 17, 2021

Accepted: Jun 3, 2021

Correspondence to

Seung-Hyuk Choi, MD, PhD

Division of Cardiology, Department of

Medicine, Heart Vascular Stroke Institute,

Samsung Medical Center, Sungkyunkwan

University School of Medicine, 81, Irwon-ro,

Gangnam-gu, Seoul 06351, Korea.

E-mail: sh1214.choi@samsung.com

Copyright $\odot$ 2021. The Korean Society of Cardiology

This is an Open Access article distributed under the terms of the Creative Commons Attribution Non-Commercial License (https:// creativecommons.org/licenses/by-nc/4.0) which permits unrestricted noncommercial use, distribution, and reproduction in any medium, provided the original work is properly cited.

ORCID iDs

Ki Hong Choi (D)

https://orcid.org/0000-0001-7511-9581

Seung-Hyuk Choi (D)

https://orcid.org/0000-0002-0304-6317

Funding

The authors received no financial support for the research, authorship, and/or publication of this article.

Conflict of Interest

The authors declare that there is no conflict of interest relevant to this work.

\section{Current Status and Future Perspectives of Renal Denervation}

\author{
Ki Hong Choi $\mathbb{1}$, MD, and Seung-Hyuk Choi $\mathbb{1}$, MD, PhD
}

Division of Cardiology, Department of Internal Medicine, Heart Vascular Stroke Institute, Samsung Medical Center, Sungkyunkwan University School of Medicine, Seoul, Korea

\section{AUTHOR'S SUMMARY}

Despite the availability of numerous antihypertensive medications, hypertension treatment and control rates remain low, and uncontrolled hypertension is well-known to be one of the most important cardiovascular risk factors. Endovascular catheter-based renal denervation (RDN) has been developed to be a complementary or alternative treatment option for patients who cannot take medication, poor adherence, or have resistant hypertension despite the use of maximal doses of medications. Recently, several randomized trials for evaluating the efficacy and safety of second-generation RDN devices consistently show solid evidence for their blood pressure-lowering efficacy. This review summarizes the current evidence and future perspectives of RDN.

\section{ABSTRACT}

Catheter-based renal denervation (RDN) therapy, a new procedure that uses radiofrequency ablation to interrupt efferent and afferent renal sympathetic nerve fibers, is a complementary or alternative treatment to antihypertensive medications for optimal control of blood pressure (BP). Although several single-arm early proof-of-concept studies showed significant $\mathrm{BP}$ reduction, the largest sham-controlled study using the first-generation RDN device (SYMPLICITY HTN-3) failed to significantly reduce BP in patients with resistant hypertension who were taking the guideline-based combination of antihypertensive medications.

Since then, new devices and techniques have been developed to improve the efficacy and safety of RDN procedures. Sham-controlled trials using second-generation RDN devices (radiofrequency- and ultrasound-based) have provided solid evidence for their BP-lowering efficacy with and without the use of concomitant antihypertensive medication. Moreover, the safety profile of RDN in several registries and clinical trials appears to be excellent. This review summarizes the current evidence for RDN and discusses its current issues, future trials, Asian perspectives, and potential roles in both hypertension and other morbidities.

Keywords: Renal denervation; Blood pressure; Resistant hypertension; Asia 
Data Sharing Statement

The data required to reproduce these findings cannot be shared because this is a narrative summary, and the author does not have access to the data or the authority to share the data.

\section{Author Contributions}

Conceptualization: Choi SH; Investigation: Choi KH; Methodology: Choi KH; Supervision: Choi SH; Writing - original draft: Choi KH; Writing - review \& editing: Choi SH.

\section{INTRODUCTION}

Hypertension (HTN) is a well-known, powerful risk factor of cardiovascular disease (CVD), and its prevalence has been rising worldwide. ${ }^{1-3)}$ Previous clinical trials have shown that treating HTN reduced the risk of all-cause mortality and CVD, including stroke, myocardial infarction, and heart failure. ${ }^{4-7)}$ More importantly, the Systolic Blood Pressure Intervention Trial (SPRINT) demonstrated that intensive blood pressure (BP) control (targeting a systolic $\mathrm{BP}$ of less than $120 \mathrm{mmHg}$ ), compared with standard control (targeting a systolic BP of less than $140 \mathrm{mmHg}$ ), reduced rates of major adverse cardiovascular events in patients at high risk for CVD without diabetes mellitus. ${ }^{8}$ Based on that result, the current relevant guidelines recommend treatment thresholds for the initiation of antihypertensive drugs and target $\mathrm{BP}$ ranges that are lower than those in the previous guidelines as long as patients tolerate the treatment. ${ }^{9-11}$ Nevertheless, in real-world practice, BP control rates are still low, and the prevalence of resistant HTN continues to increase globally. ${ }^{12) 13}$ One of the factors affecting that result is poor adherence to prescribed antihypertensive medications. In fact, previous large observational studies have shown that roughly half of participants stop taking their antihypertensive drugs within a year for various reasons, including poor patient compliance, adverse effects of drug therapy, and socioeconomic factors, ${ }^{14115)}$ and non-persistence or low adherence to antihypertensive treatment was associated with future adverse outcomes. ${ }^{16-19)}$ In this regard, patients who cannot take medication or poorly adhere to their prescribed regimen might need additional or alternative treatment options for adequate BP control, and device-based BP-lowering therapy such as renal denervation (RDN) could be a complementary or alternative treatment option for those patients. ${ }^{20-22)}$ In this review, we discuss the current evidence, issues, future trials, and potential roles of RDN as an attractive treatment option for HTN.

\section{PATHOPHYSIOLOGICAL RATIONALE}

Although the pathophysiology of HTN is complicated, the renal sympathetic nervous system, which contains both afferent and efferent sympathetic nerve fibers, plays an essential role in the development of HTN. ${ }^{23}$ Concretely, activation of the efferent sympathetic nerves in the renal artery can lead to renal arteriolar vasoconstriction, decreased renal blood flow, increased renin secretion, subsequent activation of the angiotensin-aldosterone system, and increased sodium and water absorption, resulting in increased intravascular volume and the maintenance of systemic HTN. ${ }^{24)}$ On the other hand, activation of renal afferent nerves can lead to increased systemic sympathetic activity and hormone release in the hypothalamus, resulting in increased systemic vascular resistance and HTN. ${ }^{25}$ Therefore, RDN, which interrupts both efferent and afferent sympathetic sensory nerve pathways in the renal artery, has been developed for the treatment of HTN.

\section{EVIDENCE FOR THE FIRST-GENERATION DEVICE}

The first-generation radiofrequency $(\mathrm{RF})$ ablation system for performing RDN was a single unipolar electrode on a flexible (4 French) catheter (SYMPLICITY Flex ${ }^{\mathrm{TM}}$; Medtronic, Minneapolis, MN, USA). In 2009, Krum et al ${ }^{26)}$ conducted a proof-of-concept study (SYMPLICITY HTN-1) and demonstrated the feasibility of RDN in patients with resistant HTN. In that study, office BP was decreased by up to $27 \mathrm{mmHg}$ (systolic BP) and $17 \mathrm{mmHg}$ 
(diastolic $\mathrm{BP}) 12$ months after the $\mathrm{RDN}$ procedure without serious procedure-related adverse events. Subsequently, the open-label randomized controlled SYMPLICITY HTN-2 trial also showed that the RDN group was associated with significant BP reduction at the 6-month follow-up, compared with control group (RDN vs. control group, $-32 / 12 \mathrm{mmHg}$ vs. $1 / 0 \mathrm{mmHg}, \mathrm{p}<0.001$ ) in patients with treatment-resistant essential HTN (defined as office systolic $\mathrm{BP} \geq 160 \mathrm{mmHg}$ despite the prescription of $\geq 3$ antihypertensive drugs). ${ }^{27)}$ Most observational studies and registries showed similarly promising findings. ${ }^{28-30}$

In 2014, to overcome the methodologic shortcomings, particularly the lack of blinding, in the SYMPLCITY HTN-2 trial, an additional multicenter, single-blind, randomized shamcontrolled trial (the SYMPLICITY HTN-3 trial) was conducted in patients with resistant HTN (defined as office systolic BP $\geq 160 \mathrm{mmHg}$ despite the prescription of $\geq 3$ antihypertensive drugs) ${ }^{31}{ }^{31}$ In that study, 535 patients with resistant HTN were randomly assigned in a 2:1 ratio to undergo RDN or a sham procedure. Unexpectedly, the early excitement about RDN ended abruptly when the results of the SYMPLICITY HTN-3 trial failed to demonstrate the superiority of RDN over sham treatment for office BP changes at 6 months. In the SYMPLICITY HTN -3 trial, the mean change in office systolic BP at 6 months was $-14.13 \pm$ $23.93 \mathrm{mmHg}$ in the RDN group ( $\mathrm{p}<0.001$ for comparisons with baseline) and $-11.74 \pm 25.94$ $\mathrm{mmHg}$ in the sham-procedure group ( $\mathrm{p}<0.001$ for comparisons with baseline), without a significant between-group difference (difference of $-2.39 \mathrm{mmHg}$; 95\% confidence interval [CI], -6.89 to $2.12 \mathrm{mmHg}$; for superiority $=0.26$ with a margin of $5 \mathrm{mmHg}$ ), although the safety endpoints did not differ significantly between the two groups either. ${ }^{31}$ Several possible explanations have been proposed to account for the discrepancy between the results of the SYMPLICITY HTN-3 trial and the results of previous studies and registries, including the SYMPLICITY HTN -1 and -2 trials. First, 39\% of patients underwent antihypertensive medication changes during the study period. Furthermore, trial participation might have affected the high degree of adherence to antihypertensive therapy found among the participants because of close follow-up, which might be associated with the unexpectedly large BP reduction in the sham group. Second, patients with isolated systolic HTN were included in the SYMPLICITY HTN-3 trial. Mahfoud et al. reported that changes in isolated systolic HTN following RDN was less pronounced than BP reduction in patients with combined systolic and diastolic HTN. ${ }^{32}$ Third, due to the limitations of operator experience with RDN, only a few patients in the RDN group received the complete circumferential ablation pattern in the main renal arteries recommended in the protocol. Actually, the number of ablations was associated with the degree of BP reduction in post-hoc analysis of SYMPLICITY HTN-3 trial data. ${ }^{33)}$

Beyond the SYMPLCITY HTN-1, -2 , and -3 trials, several other randomized controlled trials and registries have been published about the first-generation RDN device, and Table 1 summarizes the results of those studies. ${ }^{34-43}$ Among them, the issue of adherence, which is one of the weaknesses of the SYMPLICITY HTN-3 trial, was adequately addressed in the well-designed open-label randomized controlled Renal Denervation for Hypertension (DENERHTN) trial. That trial included 106 patients with well-defined and truly resistant HTN, and the patients were randomized 1:1 to receive either RDN plus standardized stepped-care antihypertensive treatment (SSAHT) or SSAHT alone. That study showed that RDN plus SSAHT reduced ambulatory systolic BP significantly better than SSAHT alone (RDN vs. control, $-15.8 \mathrm{mmHg}$ vs. $-9.9 \mathrm{mmHg}$; baseline-adjusted difference of $-5.9 \mathrm{mmHg}$; $95 \% \mathrm{CI},-11.3$ to $-0.5 \mathrm{mmHg}$; $=0.033$ ). Of note, although about $50 \%$ of the patients in both the RDN and control groups were partially or completely non-adherent to 


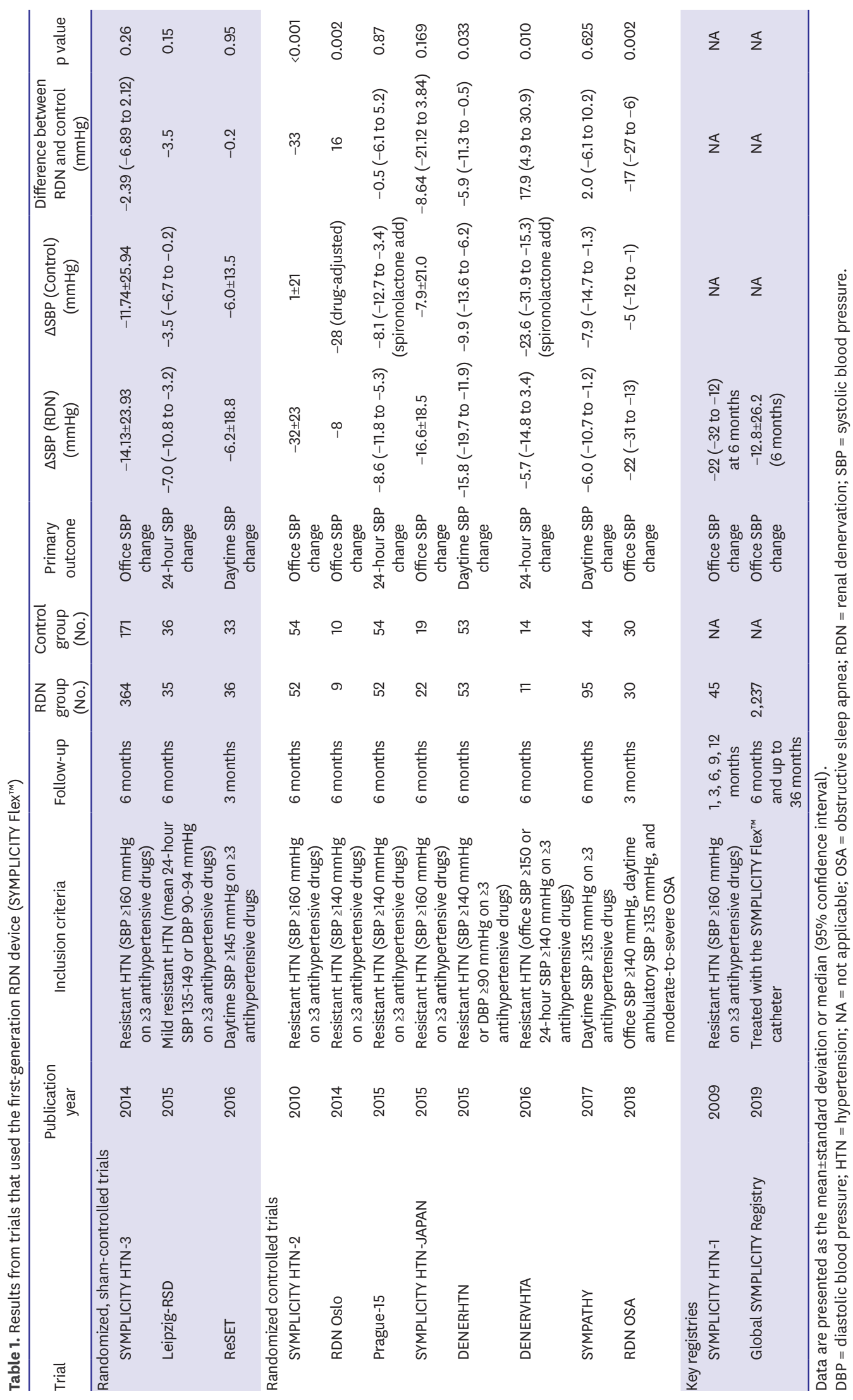


antihypertensive medications, no differences in doses or adherence rates were found between the two randomized groups. ${ }^{44)}$ Interestingly, a post-hoc analysis of the DENERHTN trial demonstrated that antihypertensive medication nonadherence was a major determinant of the difference between office systolic and daytime ambulatory BP. ${ }^{45)}$

\section{SECOND-GENERATION RENAL DENERVATION TRIALS}

\section{Radiofrequency ablation-based treatment}

Because the results of trials using a first-generation RDN device for the treatment of HTN were controversial, several subsequent preclinical and clinical studies explored ways to improve the effectiveness of RDN. ${ }^{46-48}$ For example, a second-generation RF ablation device (SYMPLICITY Spyral ${ }^{\mathrm{TM}}$; Medtronic), a flexible 4-electrode catheter design used to perform 4 simultaneous ablations with a helical pattern, was developed. This system can perform a comprehensive RDN procedure that includes ablation in the distal main renal artery and arterial branches. Based on the lessons learned from the pitfalls of the SYMPLICITY HTN-3 study, two well-designed, randomized, sham-controlled, pilot trials of the second-generation multielectrode SPYRAL RF ablation device were conducted. ${ }^{49}$ (50) Those trials enrolled patients with mild to moderate combined systolic and diastolic HTN (defined as office systolic BP $\geq 150 \mathrm{mmHg}$ and $<180 \mathrm{mmHg}$, office diastolic BP $\geq 90 \mathrm{mmHg}$, and mean 24-hour ambulatory systolic BP $\geq 140 \mathrm{mmHg}$ and $<170 \mathrm{mmHg}$ ) in the absence (SPYRAL HTN-OFF MED trial) or presence (SPYRAL HTN-ON MED trial) of antihypertensive medication. Based on the previous results of a randomized trial comparing the effectiveness of $\mathrm{BP}$ reduction between $\mathrm{RF}$ ablation at distal renal arterial branches beyond the main renal artery vs. conventional main renal artery treatment, ${ }^{51}$ all previously experienced RDN operators who participated in these studies were advised to perform RF ablation at all accessible renal arteries, including distal segments and subsequent branches, using a multi-electrode catheter. Furthermore, medication adherence was strictly evaluated by urine or serum assays both before and after the RDN or sham treatment in the SPYRAL HTN-ON MED study to identify the effect that adherence had on the endpoints. In the prospectively planned interim analyses of the first 80 patients enrolled in the SPYRAL HTN-OFF MED study, the RDN group showed a significant reduction in mean 24-hour ambulatory systolic BP from baseline to 3 months $(-5.5 \mathrm{mmHg}$; $95 \% \mathrm{CI},-9.1$ to $-2.0 \mathrm{mmHg}$; $=0.003)$, but the sham procedure group saw no significant difference $(-0.5 \mathrm{mmHg}$; $95 \% \mathrm{CI},-3.9$ to $2.9 \mathrm{mmHg}$; $=0.76$; difference between groups -5.0 mmHg; 95\% CI, -9.9 to $-0.2 \mathrm{mmHg}$; $=0.041$ ). The SPYRAL HTN-ON MED trial of patients taking one to three antihypertensive medications also demonstrated that 24-hour ambulatory systolic BP decreased significantly from baseline to 6 months in the RDN group $(-9.0 \mathrm{mmHg}$; $95 \%$ CI, -12.7 to $-5.3 \mathrm{mmHg}$; $\mathrm{p}<0.001)$ but not in the sham procedure group $(-1.6 \mathrm{mmHg}$; $95 \% \mathrm{CI},-5.2$ to $2.0 \mathrm{mmHg} ; \mathrm{p}=0.365)$, with significant between-group differences $(-7.4$ $\mathrm{mmHg}$; $95 \% \mathrm{CI},-12.5$ to $-2.3 \mathrm{mmHg}$; $=0.005$ ). Interestingly, similar to the DENERHTN trial, the patient adherence rate to the prescribed antihypertensive medications was about $60 \%$ and did not differ significantly between the RDN and control groups at 3 or 6 months. Recently, the sham-controlled SPYRAL HTN-OFF MED Pivotal trial was published and was adequately powered for the primary efficacy endpoint. ${ }^{52)} \mathrm{A}$ total of 331 patients was recruited using a combination of data from pilot $(n=80)$ and pivotal $(n=251)$ trials. A Bayesian approach was used for the primary analyses. The treatment difference between the RDN and sham control groups for 24-hour systolic BP was $-4.0 \mathrm{~mm} \mathrm{Hg}$ (Bayesian 95\% credible interval, -6.2 to $-1.8 \mathrm{mmHg} ; \mathrm{p}=0.001$ ), and for office systolic BP, the difference was $-6.6 \mathrm{~mm} \mathrm{Hg}$ (Bayesian 95\% credible interval, -9.6 to $-3.5 \mathrm{mmHg}$; $\mathrm{p}<0.001$ ). There was no difference in 
major device-related or procedural-related safety events between the two groups for up to 3 months. The prospectively powered sham-controlled SPYRAL HTN-ON MED Expansion trial is currently ongoing (ClinicalTrials.gov, NCT02439775). The results of these trials are expected to consolidate support for RDN as a treatment for HTN. Beyond the SYMPLICITY Flex $^{\mathrm{TM}}$ and Spyral ${ }^{\mathrm{TM}}$ ablation catheters, other RF ablation systems have been developed and approved for use in Europe (EnligHTN [St. Jude Medical, St. Paul, MN, USA], Vessix [Boston Scientific, Marlborough, Massachusetts, USA], OneShot [Covidien, Dublin, OH, USA], and Iberis [Terumo, Ann Arbor, MI, USA]), China (GL-06E15WA ablator and GL-6W ablation catheter [Shanghai Golden Leaf Medtech Company, Shanghai, China]), and Korea (DENEX ${ }^{\mathrm{TM}}$ [Handok Kalos Medical, Seoul, Korea]). ${ }^{53-58}$ However, those devices still need their efficacy and safety proven in well-designed, randomized, sham-controlled trials. Among them, the recent randomized, sham-controlled Renal Denervation Using the Vessix Renal Denervation System for the Treatment of Hypertension (REDUCE HTN REINFORCE) trial evaluated the efficacy of balloon-type bipolar RF-based RDN devices (Vessix; Boston Scientific). ${ }^{59)}$ Although enrollment was terminated early for apparent futility before a sample sufficient for powered efficacy comparisons was enrolled, a significant difference in office systolic BP reduction in favor of $\mathrm{RDN}$ was reported at 6 and 12 months.

\section{Ultrasound-based treatment}

An alternative technology using balloon-type ultrasonic RDN catheters (ReCor Medical, Palo Alto, CA, USA) allows complete circumferential denervation in a more reliable fashion than $\mathrm{RF}$ ablation by generating frictional heating through the interaction of high-frequency sound waves that pass through the surrounding fluids. ${ }^{60}$ The multicenter, randomized, sham-controlled RADIANCE-HTN SOLO (patients with mild to moderate HTN without antihypertensive medications) and TRIO (patients with uncontrolled HTN receiving 3 antihypertensive medications) trials were conducted to evaluate the safety and efficacy of the ultrasound-based RDN procedure. In the RADIANCE HTN Solo trial, 146 patients with combined systolic and diastolic HTN (daytime ambulatory BP $\geq 135 / 85 \mathrm{mmHg}$ and $<170 / 105$ $\mathrm{mmHg}$ ) after discontinuing a maximum of two antihypertensive medications for 4 weeks before the ambulatory BP assessment were recruited. ${ }^{61)}$ After 2 months, the reduction in daytime ambulatory systolic BP was significantly greater with $\mathrm{RDN}(-5.9 \pm 9.3 \mathrm{mmHg})$ than with the sham procedure $(-2.2 \pm 10.0 \mathrm{mmHg}$, baseline-adjusted difference between groups: $-6.3 \mathrm{~mm}$ $\mathrm{Hg} ; 95 \% \mathrm{CI},-9.4$ to $-3.1 ; \mathrm{p}<0 \cdot 001)$. Between 2 and 6 months after randomization, patients in both groups were restarted on antihypertensive drugs according to a standardized drug titration protocol if their average home BP was $\geq 135 / 85 \mathrm{mmHg}$. At 6 months, greater reduction in daytime ambulatory systolic BP was maintained in the RDN group than in the sham control group (difference adjusted for baseline BP and number of medications $-4.3 \mathrm{mmHg} ; 95 \% \mathrm{CI}$, -7.9 to $-0.6 \mathrm{mmHg} ; \mathrm{p}=0.024$ ), despite being prescribed fewer antihypertensive medications than in the sham group (RDN vs. sham procedure, $65.2 \%$ vs. $84.5 \%$; $\mathrm{p}=0.008$ ). ${ }^{62)}$ Between 6 and 12 months (unblinded phase), patients received antihypertensive medications at their physicians' preference. The decrease in daytime ambulatory systolic BP from baseline to 12 months in the RDN group was stably maintained, despite taking fewer prescribed medications than the sham procedure group (number of medications for RDN vs. sham, 1.0 vs. 1.4; $\mathrm{p}=0.015$ ). However, the mean between-group difference in daytime ambulatory systolic BP change adjusted for the number of antihypertensive medications was not significant at 12 months $(-2.3 \mathrm{mmHg} ; 95 \% \mathrm{CI},-5.9$ to $1.3 ; \mathrm{p}=0.201){ }^{63}{ }^{63}$ In the recently published RADIANCE HTN TRIO trial, 136 patients with resistant HTN (defined as office $\mathrm{BP} \geq 140 / 90 \mathrm{mmHg}$ despite the prescription of $\geq 3$ antihypertensive drugs, and daytime ambulatory $\mathrm{BP} \geq 135 / 85$ $\mathrm{mmHg} 4$ weeks after switching a single-pill, fixed-dose, daily combination of amlodipine 10 
$\mathrm{mg}$, valsartan $160 \mathrm{mg}$ [or Olmesartan $40 \mathrm{mg}$ ], and hydrochlorothiazide $25 \mathrm{mg}$ ) were finally enrolled. ${ }^{64)}$ Full adherence to the combination medications at 2 months were similar between the two groups ( $R D N$ vs. sham, $82 \%$ vs. $82 \%$; $p=0.99$ ). After 2 months, RDN procedure significantly reduced daytime ambulatory systolic BP more than the sham procedure (RDN vs. sham, $-8.0 \mathrm{mmHg}$ [interquartile range from -16.4 to $0.0 \mathrm{mmHg}$ ], vs. $-3.0 \mathrm{mmHg}$ [interquartile range from -10.3 to $1.8 \mathrm{mmHg}$; ; group difference $-4.5 \mathrm{mmHg}$; $95 \% \mathrm{CI},-8.5$ to -0.3 ; adjusted $\mathrm{p}=0.022$ ) without serious procedure-related adverse events. The currently ongoing REQUIRE (Korea and Japan, ClinicalTrials.gov, NCT02918305) trials will be helpful in determining the safety and efficacy of ultrasound-based RDN procedures for Asian patients with drug-resistant HTN taking standard antihypertensive medicines.

\section{Ethanol injection-based treatment}

The Peregrine catheter (Ablative Solutions, San Jose, CA, USA) was developed to deliver ethanol directly into the adventitial and periadventitial tissue of renal arteries. The preclinical study in a porcine model identified a linear dose-response between the injected alcohol volume and norepinephrine reduction in the renal artery ${ }^{65)}$ A prospective, multi-center, open-label trial showed that 6 months after performing the Peregrine catheter procedure, the mean 24-hour ambulatory BP was significantly reduced compared with baseline. ${ }^{66)}$ This device is currently under investigation in a randomized, sham-controlled trial in hypertensive patients taking (TARGET BP I, ClinicalTrials.gov, NCT02910414) and not taking (TARGET BP OFF-MED, ClinicalTrials.gov, NCT03503773) antihypertensive medications.

\section{COMPARISON BETWEEN RADIOFREQUENCY ABLATION AND ULTRASOUND BASED RENAL DENERVATION}

A recent randomized, single-blind trial was conducted to compare the $\mathrm{BP}$ lowering effects of three treatment arms: ultrasound-based (PARADISE catheter) and RF ablation-based (SYMPLICITY Spyral ${ }^{\mathrm{TM}}$ catheter) RDN of the main renal artery, and RF ablation-based RDN of the main renal arteries, side branches, and accessories in patients with resistant HTN (office systolic $\mathrm{BP}>160 \mathrm{~mm} \mathrm{Hg}$ or diastolic $\mathrm{BP}>90 \mathrm{~mm} \mathrm{Hg}$ diastolic despite treatment with $\geq 3$ different classes of antihypertensive drugs, including at least 1 diuretic unless intolerant to diuretics). ${ }^{67}$ Although daytime ambulatory systolic BP was reduced more in the ultrasound-based treatment group at 3 months than in the group with RF ablation of the main renal artery $(-13.2 \pm 13.7$ vs. $-6.5 \pm 10.3 \mathrm{mmHg}$; mean difference, $-6.7 \mathrm{mmHg}$; $=0.038$ ), no significant difference in systolic BP change was observed between the ultrasound-based treatment group and the group with main renal artery and side branch ablation $(-8.3 \pm 11.7 \mathrm{mmHg}$ for additional side branch ablation; mean difference $-1.8 \mathrm{mmHg}$; adjusted $\mathrm{p}>0.99$ ). This result might be because ultrasound energy has deeper penetration and offers more complete renal nerve ablation of the main renal artery than the RF ablation of the main renal artery alone. Nevertheless, this result should be interpreted with caution due to the limitations of this study, including the lack of a sham-control, lack of information about drug adherence tracking, and small sample size.

\section{SAFETY OF RENAL DENERVATION}

In contrast to antihypertensive medications, the safety of device-based therapies for HTN focuses on procedural complications. Renal artery injury, vascular access site complications, and deterioration in kidney function were the most anticipated complications after the RDN 
procedure. However, the safety profile of RDN in several registries and clinical trials appears to be excellent. A recent meta-analysis of 50 published RDN trials reported on procedural safety ${ }^{68}{ }^{67}$ Among 5,769 subjects with 10,249 patient-years of follow-up, only 26 patients were found to have renal artery stenosis or dissection $(0.45 \%)$. The 3-year safety data from the largest database, the prospective, open-label Global SYMPLICITY registry, also demonstrated an extremely low incidence of peri-procedural complications and adverse events. ${ }^{43}$

\section{ETHNIC DIFFERENCES FOR ASIANS}

It is well-known that there are significant ethnic differences in the determinants of HTN and the risk of HTN-related CVD. ${ }^{69-71)}$ In general, the prevalence of HTN in Asia is similar to that in other countries, despite a lower prevalence of metabolic syndrome. In addition, the association between BP and CVD, especially for hemorrhagic stroke and non-ischemic heart failure, is stronger in Asian patients than in white patients. ${ }^{7173)}$ Masked HTN (defined as normal office BP and elevated out-of-office BP), which is associated with increased sympathetic activity, is more prevalent in Asians than in Westerners. ${ }^{74-76}$ East Asian populations in particular have at least a 2 -fold higher sensitivity to the $\beta$-blocking effects of propranolol than white populations. ${ }^{77)}$ Taken together, these ethnic differences indicate that Asian populations might be particularly sensitive to sympathetic modulation, thereby making the RDN procedure an attractive BP-lowering strategy for Asian patients. ${ }^{78)}$

The SYMPLICITY HTN-Japan randomized trial using the first-generation RDN device (SYMPLICITY Flex ${ }^{\mathrm{TM}}$; Medtronic) was the first published information specifically about the efficacy of RDN in an Asian population with resistant HTN. ${ }^{38}$ Although this trial did not provide conclusive information about the effects of RDN due to its small sample size and early discontinuation, the magnitude of office systolic BP reduction 6 months after the RDN procedure $(-16.6 \pm 18.5 \mathrm{mmHg})$ was numerically greater than that in the SYMPLICITY HTN-3 trial $(-14.13 \pm 23.93 \mathrm{~mm} \mathrm{Hg})$, in which the study population was mainly white and Black people. In Korea, the first successful percutaneous RDN using the first-generation device was used to treat a hypertensive patient with congestive heart failure in 2013. ${ }^{79}$ After that, a sub-analysis of the Global SYMPLICITY Registry evaluated the outcomes of the RDN procedure among patients from Korea ${ }^{80)}$ Compared with Caucasians with uncontrolled HTN, the Korean patients were younger, had a lower body mass index, a lower baseline systolic BP, and a higher prevalence of $\mathrm{CVD}$, such as stroke, myocardial infarction, or angina. After propensity score matching, the Koreans had a systolic BP change similar to that of Caucasians at 6 months $(-19.4 \pm 17.2 \mathrm{mmHg}$ vs. $-20.9 \pm 21.4 \mathrm{mmHg}$; adjusted $\mathrm{p}=0.998$ ), whereas the change in $\mathrm{BP}$ reduction was significantly higher in Koreans than in Caucasians $(-27.2 \pm 18.1 \mathrm{mmHg}$ vs. $-20.1 \pm 23.9 \mathrm{mmHg}$; adjusted $\mathrm{p}=0.002$ ) at 12 months. The RDN procedural characteristics did not differ significantly between the two ethnic groups. Thus, the responsiveness of Asian patients to the RDN procedure appears to be at least equivalent to that of Westerners for the reduction of BP. Nevertheless, more evidence using the current generation of RDN devices is needed to confirm these findings.

\section{FUTURE DIRECTIONS OF RENAL DENERVATION BEYOND HYPERTENSION}

The randomized, sham-controlled trial results for multipolar RF- and ultrasound-based second-generation RDN devices are summarized in Figure 1. Although these trials and 


\begin{tabular}{|c|c|c|c|c|c|c|}
\hline & $\begin{array}{l}\text { SPYRAL HTN- } \\
\text { ON MED Pilot }\end{array}$ & $\begin{array}{l}\text { SPYRAL HTN- } \\
\text { OFF MED Pilot }\end{array}$ & $\begin{array}{l}\text { SPYRAL HTN- } \\
\text { OFF MED Pivotal }\end{array}$ & $\begin{array}{l}\text { REDUCE HTN } \\
\text { REINFORCE }\end{array}$ & $\begin{array}{l}\text { RADIANCE-HTN } \\
\text { SOLO }\end{array}$ & $\begin{array}{c}\text { RADIANCE-HTN } \\
\text { TRIO }\end{array}$ \\
\hline $\begin{array}{l}\text { Inclusion } \\
\text { criteria }\end{array}$ & $\begin{array}{l}\text { SBP } 150-180, \text { DBP } \geq 90, \\
\text { and mean } 24 \text {-hour } \\
\text { ambulatory } \\
\text { SBP } 140-170 \text { on med }\end{array}$ & $\begin{array}{l}\text { SBP 150-180, DBP } \geq 90 \text {, } \\
\text { and mean } 24 \text {-hour } \\
\text { ambulatory } \\
\text { SBP } 140-170 \text { off med }\end{array}$ & $\begin{array}{l}\text { SBP } 150-180, \mathrm{DBP} \geq 90 \text {, } \\
\text { and mean } 24 \text {-hour } \\
\text { ambulatory } \\
\text { SBP } 140-170 \text { off med }\end{array}$ & $\begin{array}{l}\text { SBP 150-180 } \\
\text { and mean 24-hour } \\
\text { ambulatory } \\
\text { SBP 135-170 off med }\end{array}$ & $\begin{array}{l}\text { Daytime ambulatory } \\
\mathrm{BP} \geq 135 / 85 \mathrm{mmHg} \text {, and } \\
<170 / 105 \mathrm{mmHg} \text { off med }\end{array}$ & $\begin{array}{c}\mathrm{SBP} \geq 140, \mathrm{DBP} \geq 90 \text {, } \\
\text { and mean } 24 \text {-hour } \\
\text { ambulatory } \\
\mathrm{BP} \geq 135 / 85 \text { on med }\end{array}$ \\
\hline Device & SYMPLICITY Spyral'TM & SYMPLICITY Spyral ${ }^{\top M}$ & SYMPLICITY Spyral' ${ }^{T M}$ & Vessix & PARADISE & PARADISE \\
\hline Follow-up & 6 months & 3 months & 3 months & 6 months & 2 months & 2 months \\
\hline Sample size & 80 & 80 & 331 (251 pivotal +80 pilot) & 51 & 146 & 136 \\
\hline Group & RDN Sham & RDN Sham & RDN Sham & RDN Sham & RDN Sham & RDN Sham \\
\hline $\begin{array}{r}\text { Baseline } \\
\text { SBP }\end{array}$ & $152 \quad 151$ & $153 \quad 152$ & $151 \quad 151$ & 166166 & $143 \quad 144$ & 162164 \\
\hline
\end{tabular}

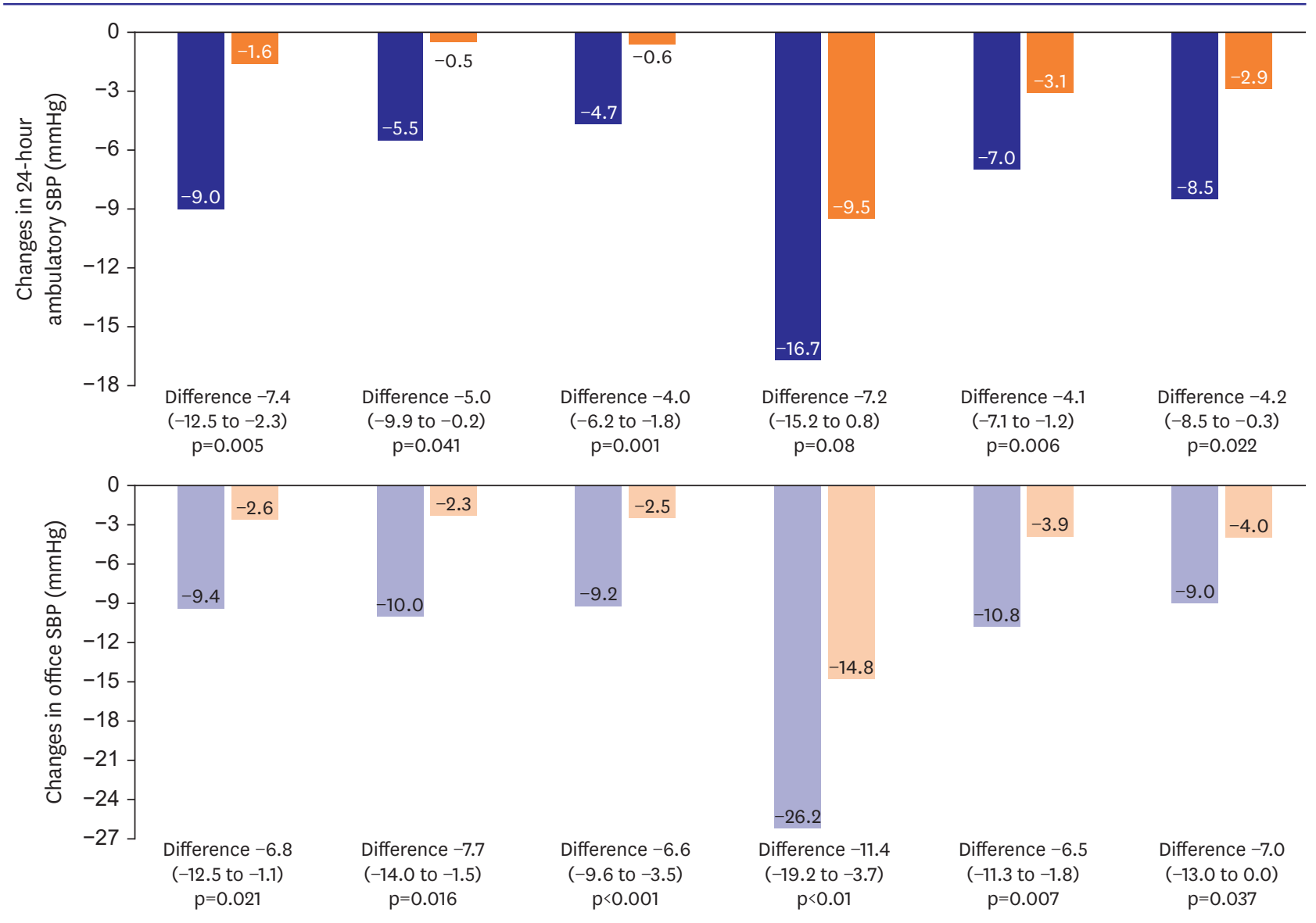

Figure 1. BP Changes with second-generation RDN devices in recently published randomized, sham-controlled trials.

Changes in 24-hour ambulatory systolic BP and office SBP in the landmark randomized, sham-controlled trials using second-generation RDN devices are presented. $\mathrm{BP}=$ blood pressure; $\mathrm{DBP}=$ diastolic blood pressure; $\mathrm{RDN}=$ renal denervation; $\mathrm{SBP}=$ systolic blood pressure. 


\section{Heart failure}

Theoretically, excessive and prolonged activation of the sympathetic nervous system plays a key role in the pathological remodeling of the cardiac structure in patients with heart failure, ${ }^{84)}$ and the use of a beta-blocker or renin-angiotensin system blockade, which affects the regulation of the sympathetic signaling pathway, has been associated with a reduced risk of morbidity in heart failure patients with reduced ejection fraction. ${ }^{85-90)}$ Furthermore, Brandt et al. ${ }^{91)}$ previously documented that RDN significantly reduced the left ventricular mass index, improved diastolic function, reduced interventricular septum thickness, decreased end-systolic volume, and improved ejection fraction. Therefore, the REACH-Pilot study was conducted to evaluate the efficacy and safety of the RDN procedure for patients with chronic systolic heart failure. Patients showed improvements in both symptoms and exercise capacity without peri-procedural complications 6 months after the RDN. ${ }^{92}$ However, the Renal Denervation in Heart Failure with Preserved Ejection Fraction (RDT-PEF) trial was terminated early because of difficulties in recruitment, leaving it underpowered to detect whether RDN improved the endpoints of quality of life, exercise function, biomarkers, and left heart remodeling in patients with heart failure with preserved ejection fraction. ${ }^{93}$ Therefore, future randomized, adequately powered, blinded, sham-controlled clinical trials are required to determine the effects of RDN on the morbidity of heart failure patients with reduced or preserved ejection fraction.

\section{Atrial fibrillation}

Sympathetic activation, particularly in association with para-sympathetic withdrawal, produces arrhythmias such as atrial fibrillation (AF). ${ }^{94)} \mathrm{A}$ randomized trial to evaluate the adjunctive effects of RDN on pulmonary vein isolation (PVI) for the treatment of refractory $\mathrm{AF}$ and drug-resistant $\mathrm{HTN}$ demonstrated that RDN reduces systolic and diastolic BP in patients with drug-resistant HTN and reduces AF recurrence. ${ }^{95}$ In addition, the larger Evaluate Renal Artery Denervation In Addition To Eliminate Atrial Fibrillation (ERADICATEAF) trial also showed that adding RDN to PVI, compared with PVI alone, significantly increased the likelihood of freedom from AF 12 months later among patients with paroxysmal AF and HTN. ${ }^{96)}$ These results suggest that RDN could be an attractive new treatment addition to PVI for patients with AF.

\section{Chronic kidney disease}

Patients with chronic kidney disease (CKD) are often refractory to drug treatment, even with the combination of several antihypertensive medications. ${ }^{97)}$ Therefore, RDN might be a potentially beneficial intervention to treat the sympathetic activation associated with both HTN and CKD. However, most previous randomized trials of RDN have excluded patients with advanced CKD or end-stage renal disease due to concerns about renal safety. Observational studies have consistently shown that RDN was associated with significant BP-lowering effects without deteriorating the glomerular filtration rates of patients with $\mathrm{CKD}^{98-100)}$ or end-stage renal disease. ${ }^{101)}$ Future well-designed randomized outcomes studies in patients with CKD treated with and without RDN would provide interesting evidence about risk reduction in those patients.

\section{CONCLUSION}

Based on the lessons learned from the pitfalls of the SYMPLICITY HTN-3 trial, improvements in device design (spiral type or ultrasound-mediated), technique (main renal artery and 
distal branch ablation), and trial design (control for adherence) have made RDN an attractive treatment option for HTN. Future trials need to focus on cardiovascular outcomes as well as BP reduction, adequate patient selection to show the greatest benefit, completeness of ablation without significant peri-procedural complications, and potential roles in treating other morbidities characterized by sympathetic overactivity. Furthermore, evidence is needed for the benefits of second-generation RDN devices in Asian patients.

\section{REFERENCES}

1. GBD 2017 Risk Factor Collaborators. Global, regional, and national comparative risk assessment of 84 behavioural, environmental and occupational, and metabolic risks or clusters of risks for 195 countries and territories, 1990-2017: a systematic analysis for the Global Burden of Disease Study 2017. Lancet 2018;392:1923-94. PUBMED | CROSSREF

2. Fuchs FD, Whelton PK. High blood pressure and cardiovascular disease. Hypertension 2020;75:285-92. PUBMED | CROSSREF

3. Mills KT, Stefanescu A, He J. The global epidemiology of hypertension. Nat Rev Nephrol 2020;16:223-37. PUBMED | CROSSREF

4. Ettehad D, Emdin CA, Kiran A, et al. Blood pressure lowering for prevention of cardiovascular disease and death: a systematic review and meta-analysis. Lancet 2016;387:957-67.

PUBMED | CROSSREF

5. Chobanian AV, Bakris GL, Black HR, et al. The seventh report of the Joint National Committee on Prevention, Detection, Evaluation, and Treatment of High Blood Pressure: the JNC 7 report. JAMA 2003;289:2560-72. PUBMED | CROSSREF

6. Neal B, MacMahon S, Chapman N; Blood Pressure Lowering Treatment Trialists' Collaboration. Effects of ACE inhibitors, calcium antagonists, and other blood-pressure-lowering drugs: results of prospectively designed overviews of randomised trials. Blood Pressure Lowering Treatment Trialists' Collaboration. Lancet 2000;356:1955-64. PUBMED | CROSSREF

7. Psaty BM, Smith NL, Siscovick DS, et al. Health outcomes associated with antihypertensive therapies used as first-line agents. A systematic review and meta-analysis. JAMA 1997;277:739-45. PUBMED | CROSSREF

8. SPRINT Research Group, Wright JT Jr, Williamson JD, et al. A randomized trial of intensive versus standard blood-pressure control. N Engl J Med 2015;373:2103-16. PUBMED | CROSSREF

9. Williams B, Mancia G, Spiering W, et al. 2018 ESC/ESH guidelines for the management of arterial hypertension. Eur Heart J 2018;39:3021-104.

PUBMED | CROSSREF

10. Unger T, Borghi C, Charchar F, et al. 2020 International Society of Hypertension global hypertension practice guidelines. Hypertension 2020;75:1334-57. PUBMED | CROSSREF

11. Whelton PK, Carey RM, Aronow WS, et al. 2017 ACC/AHA/AAPA/ABC/ACPM/AGS/APhA/ASH/ASPC/ NMA/PCNA guideline for the prevention, detection, evaluation, and management of high blood pressure in adults: a report of the American College of Cardiology/American Heart Association Task Force on Clinical Practice Guidelines. J Am Coll Cardiol 2018;71:e127-248. PUBMED | CROSSREF

12. Mills KT, Bundy JD, Kelly TN, et al. Global disparities of hypertension prevalence and control: a systematic analysis of population-based studies from 90 countries. Circulation 2016;134:441-50. PUBMED | CROSSREF

13. NCD Risk Factor Collaboration (NCD-RisC). Worldwide trends in blood pressure from 1975 to 2015: a pooled analysis of 1479 population-based measurement studies with $19 \cdot 1$ million participants. Lancet 2017;389:37-55. PUBMED | CROSSREF

14. Vrijens B, Vincze G, Kristanto P, Urquhart J, Burnier M. Adherence to prescribed antihypertensive drug treatments: longitudinal study of electronically compiled dosing histories. BMJ 2008;336:1114-7. PUBMED | CROSSREF 
15. Tajeu GS, Kent ST, Huang L, et al. Antihypertensive medication nonpersistence and low adherence for adults <65 years initiating treatment in 2007-2014. Hypertension 2019;74:35-46. PUBMED | CROSSREF

16. Chowdhury R, Khan H, Heydon E, et al. Adherence to cardiovascular therapy: a meta-analysis of prevalence and clinical consequences. Eur Heart J 2013;34:2940-8.

PUBMED | CROSSREF

17. Corrao G, Parodi A, Nicotra F, et al. Better compliance to antihypertensive medications reduces cardiovascular risk. J Hypertens 2011;29:610-8. PUBMED | CROSSREF

18. Mazzaglia G, Ambrosioni E, Alacqua M, et al. Adherence to antihypertensive medications and cardiovascular morbidity among newly diagnosed hypertensive patients. Circulation 2009;120:1598-605. PUBMED | CROSSREF

19. Yang Q, Chang A, Ritchey MD, Loustalot F. Antihypertensive medication adherence and risk of cardiovascular disease among older adults: a population-based cohort study. J Am Heart Assoc 2017;6:e006056. PUBMED | CROSSREF

20. Lauder L, Böhm M, Mahfoud F. The current status of renal denervation for the treatment of arterial hypertension. Prog Cardiovasc Dis 2021;65:76-83. PUBMED | CROSSREF

21. Weber MA, Mahfoud F, Schmieder RE, et al. Renal denervation for treating hypertension: current scientific and clinical evidence. JACC Cardiovasc Interv 2019;12:1095-105. PUBMED | CROSSREF

22. Akinseye OA, Ralston WF, Johnson KC, Ketron LL, Womack CR, Ibebuogu UN. Renal sympathetic denervation: a comprehensive review. Curr Probl Cardiol 2021;46:100598. PUBMED | CROSSREF

23. Grassi G, Mark A, Esler M. The sympathetic nervous system alterations in human hypertension. Circ Res 2015;116:976-90. PUBMED | CROSSREF

24. DiBona GF. Neural control of the kidney: functionally specific renal sympathetic nerve fibers. Am J Physiol Regul Integr Comp Physiol 2000;279:R1517-24.

PUBMED | CROSSREF

25. Ciriello J, de Oliveira CV. Renal afferents and hypertension. Curr Hypertens Rep 2002;4:136-42. PUBMED | CROSSREF

26. Krum H, Schlaich M, Whitbourn R, et al. Catheter-based renal sympathetic denervation for resistant hypertension: a multicentre safety and proof-of-principle cohort study. Lancet 2009;373:1275-81. PUBMED | CROSSREF

27. Symplicity HTN-2 Investigators, Esler MD, Krum H, et al. Renal sympathetic denervation in patients with treatment-resistant hypertension (The Symplicity HTN-2 Trial): a randomised controlled trial. Lancet 2010;376:1903-9. PUBMED | CROSSREF

28. Mahfoud F, Ukena C, Schmieder RE, et al. Ambulatory blood pressure changes after renal sympathetic denervation in patients with resistant hypertension. Circulation 2013;128:132-40. PUBMED | CROSSREF

29. Vogel B, Kirchberger M, Zeier M, et al. Renal sympathetic denervation therapy in the real world: results from the Heidelberg registry. Clin Res Cardiol 2014;103:117-24. PUBMED | CROSSREF

30. Kaiser L, Beister T, Wiese A, et al. Results of the ALSTER BP real-world registry on renal denervation employing the Symplicity system. EuroIntervention 2014;10:157-65. PUBMED | CROSSREF

31. Bhatt DL, Kandzari DE, O'Neill WW, et al. A controlled trial of renal denervation for resistant hypertension. N Engl J Med 2014;370:1393-401.

PUBMED | CROSSREF

32. Mahfoud F, Bakris G, Bhatt DL, et al. Reduced blood pressure-lowering effect of catheter-based renal denervation in patients with isolated systolic hypertension: data from SYMPLICITY HTN-3 and the Global SYMPLICITY Registry. Eur Heart J 2017;38:93-100. PUBMED | CROSSREF

33. Kandzari DE, Bhatt DL, Brar S, et al. Predictors of blood pressure response in the SYMPLICITY HTN-3 trial. Eur Heart J 2015;36:219-27. PUBMED | CROSSREF 
34. Desch S, Okon T, Heinemann D, et al. Randomized sham-controlled trial of renal sympathetic denervation in mild resistant hypertension. Hypertension 2015;65:1202-8.

PUBMED | CROSSREF

35. Mathiassen ON, Vase H, Bech JN, et al. Renal denervation in treatment-resistant essential hypertension. A randomized, SHAM-controlled, double-blinded 24-h blood pressure-based trial. J Hypertens 2016;34:1639-47. PUBMED | CROSSREF

36. Fadl Elmula FE, Hoffmann P, Larstorp AC, et al. Adjusted drug treatment is superior to renal sympathetic denervation in patients with true treatment-resistant hypertension. Hypertension 2014;63:991-9. PUBMED | CROSSREF

37. Rosa J, Widimský P, Toušek P, et al. Randomized comparison of renal denervation versus intensified pharmacotherapy including spironolactone in true-resistant hypertension: six-month results from the Prague-15 study. Hypertension 2015;65:407-13.

PUBMED | CROSSREF

38. Kario K, Ogawa H, Okumura K, et al. SYMPLICITY HTN-Japan: First randomized controlled trial of catheter-based renal denervation in Asian patients. Circ J 2015;79:1222-9. PUBMED | CROSSREF

39. Azizi M, Sapoval M, Gosse P, et al. Optimum and stepped care standardised antihypertensive treatment with or without renal denervation for resistant hypertension (DENERHTN): a multicentre, open-label, randomised controlled trial. Lancet 2015;385:1957-65.

PUBMED | CROSSREF

40. Oliveras A, Armario P, Clarà A, et al. Spironolactone versus sympathetic renal denervation to treat true resistant hypertension: results from the DENERVHTA study - a randomized controlled trial. J Hypertens 2016;34:1863-71. PUBMED | CROSSREF

41. de Jager RL, de Beus E, Beeftink MM, et al. Impact of medication adherence on the effect of renal denervation: the SYMPATHY trial. Hypertension 2017;69:678-84.

PUBMED | CROSSREF

42. Warchol-Celinska E, Prejbisz A, Kadziela J, et al. Renal denervation in resistant hypertension and obstructive sleep apnea: randomized proof-of-concept phase II trial. Hypertension 2018;72:381-90. PUBMED | CROSSREF

43. Mahfoud F, Böhm M, Schmieder R, et al. Effects of renal denervation on kidney function and long-term outcomes: 3-year follow-up from the Global SYMPLICITY Registry. Eur Heart J 2019;40:3474-82. PUBMED | CROSSREF

44. Azizi M, Pereira H, Hamdidouche I, et al. Adherence to antihypertensive treatment and the blood pressure-lowering effects of Renal Denervation in the Renal Denervation for Hypertension (DENERHTN) trial. Circulation 2016;134:847-57.

PUBMED | CROSSREF

45. Hamdidouche I, Gosse P, Cremer A, et al. Clinic versus ambulatory blood pressure in resistant hypertension: impact of antihypertensive medication nonadherence: a post hoc analysis the DENERHTN study. Hypertension 2019;74:1096-103. PUBMED | CROSSREF

46. Mahfoud F, Tunev S, Ewen S, et al. Impact of lesion placement on efficacy and safety of catheter-based radiofrequency renal denervation. J Am Coll Cardiol 2015;66:1766-75. PUBMED | CROSSREF

47. Fengler K, Ewen S, Höllriegel R, et al. Blood pressure response to main renal artery and combined main renal artery plus branch renal denervation in patients with resistant hypertension. J Am Heart Assoc 2017;6:e006196. PUBMED | CROSSREF

48. Henegar JR, Zhang Y, Hata C, Narciso I, Hall ME, Hall JE. Catheter-based radiofrequency renal denervation: location effects on renal norepinephrine. Am J Hypertens 2015;28:909-14. PUBMED | CROSSREF

49. Townsend RR, Mahfoud F, Kandzari DE, et al. Catheter-based renal denervation in patients with uncontrolled hypertension in the absence of antihypertensive medications (SPYRAL HTN-OFF MED): a randomised, sham-controlled, proof-of-concept trial. Lancet 2017;390:2160-70. PUBMED | CROSSREF

50. Kandzari DE, Böhm M, Mahfoud F, et al. Effect of renal denervation on blood pressure in the presence of antihypertensive drugs: 6-month efficacy and safety results from the SPYRAL HTN-ON MED proof-ofconcept randomised trial. Lancet 2018;391:2346-55.

PUBMED | CROSSREF 
51. Pekarskiy SE, Baev AE, Mordovin VF, et al. Denervation of the distal renal arterial branches vs. conventional main renal artery treatment: a randomized controlled trial for treatment of resistant hypertension. J Hypertens 2017;35:369-75. PUBMED | CROSSREF

52. Böhm M, Kario K, Kandzari DE, et al. Efficacy of catheter-based renal denervation in the absence of antihypertensive medications (SPYRAL HTN-OFF MED Pivotal): a multicentre, randomised, shamcontrolled trial. Lancet 2020;395:1444-51. PUBMED | CROSSREF

53. Worthley SG, Tsioufis CP, Worthley MI, et al. Safety and efficacy of a multi-electrode renal sympathetic denervation system in resistant hypertension: the EnligHTN I trial. Eur Heart J2013;34:2132-40. PUBMED | CROSSREF

54. Sievert H, Schofer J, Ormiston J, et al. Renal denervation with a percutaneous bipolar radiofrequency balloon catheter in patients with resistant hypertension: 6-month results from the REDUCE-HTN clinical study. EuroIntervention 2015;10:1213-20. PUBMED | CROSSREF

55. Ormiston JA, Watson T, van Pelt N, et al. First-in-human use of the OneShot ${ }^{\mathrm{TM}}$ renal denervation system from Covidien. EuroIntervention 2013;8:1090-4. PUBMED | CROSSREF

56. Kario K, Rumoroso JR, Okawara Y, et al. Renal sympathetic denervation in patients with resistant hypertension: a feasibility study. Pulse (Basel) 2019;6:137-43. PUBMED | CROSSREF

57. Li Y, Nawabi AQ, Feng Y, Dai Q, Ma G, Liu N. Safety and efficacy of a new renal denervation catheter in hypertensive patients in the absent of antihypertensive medications: a pilot study. Int J Hypertens 2019;2019:7929706. PUBMED | CROSSREF

58. Kim CJ, Chang K, Kim BK, Park CG, Jang Y. An open-label, single-arm, multicenter feasibility study evaluating the safety of catheter-based renal denervation with DENEX ${ }^{\mathrm{TM}}$ in patients with uncontrolled hypertension on standard medical therapy. Korean Circ J2021;51:43-55. PUBMED | CROSSREF

59. Weber MA, Kirtane AJ, Weir MR, et al. The REDUCE HTN: REINFORCE: randomized, sham-controlled trial of bipolar radiofrequency renal denervation for the treatment of hypertension. JACC Cardiovasc Interv 2020;13:461-70. PUBMED | CROSSREF

60. Mabin T, Sapoval M, Cabane V, Stemmett J, Iyer M. First experience with endovascular ultrasound renal denervation for the treatment of resistant hypertension. EuroIntervention 2012;8:57-61. PUBMED | CROSSREF

61. Azizi M, Schmieder RE, Mahfoud F, et al. Endovascular ultrasound renal denervation to treat hypertension (RADIANCE-HTN SOLO): a multicentre, international, single-blind, randomised, shamcontrolled trial. Lancet 2018;391:2335-45. PUBMED | CROSSREF

62. Azizi M, Schmieder RE, Mahfoud F, et al. Six-month results of treatment-blinded medication titration for hypertension control following randomization to endovascular ultrasound renal denervation or a sham procedure in the RADIANCE-HTN SOLO trial. Circulation 2019;139:2542-53. PUBMED | CROSSREF

63. Azizi M, Daemen J, Lobo MD, et al. 12-Month results from the unblinded phase of the RADIANCE-HTN SOLO trial of ultrasound renal denervation. JACC Cardiovasc Interv 2020;13:2922-33. PUBMED | CROSSREF

64. Azizi M, Sanghvi K, Saxena M, et al. Ultrasound renal denervation for hypertension resistant to a triple medication pill (RADIANCE-HTN TRIO): a randomised, multicentre, single-blind, sham-controlled trial. Lancet. 2021 [Epub ahead of print]. PUBMED | CROSSREF

65. Fischell TA, Vega F, Raju N, et al. Ethanol-mediated perivascular renal sympathetic denervation: preclinical validation of safety and efficacy in a porcine model. EuroIntervention 2013;9:140-7. PUBMED | CROSSREF

66. Mahfoud F, Renkin J, Sievert H, et al. Alcohol-mediated renal denervation using the peregrine system infusion catheter for treatment of hypertension. JACC Cardiovasc Interv 2020;13:471-84. PUBMED | CROSSREF

67. Fengler K, Rommel KP, Blazek S, et al. A three-arm randomized trial of different renal denervation devices and techniques in patients with resistant hypertension (RADIOSOUND-HTN). Circulation 2019;139:590-600. PUBMED | CROSSREF 
68. Townsend RR, Walton A, Hettrick DA, et al. Review and meta-analysis of renal artery damage following percutaneous renal denervation with radiofrequency renal artery ablation. EuroIntervention 2020;16:89-96. PUBMED | CROSSREF

69. Ueshima H, Sekikawa A, Miura K, et al. Cardiovascular disease and risk factors in Asia: a selected review. Circulation 2008;118:2702-9.

PUBMED | CROSSREF

70. Wang TD, Goto S, Bhatt DL, et al. Ethnic differences in the relationships of anthropometric measures to metabolic risk factors in Asian patients at risk of atherothrombosis: results from the REduction of Atherothrombosis for Continued Health (REACH) Registry. Metabolism 2010;59:400-8. PUBMED | CROSSREF

71. Kario K, Chen CH, Park S, et al. Consensus document on improving hypertension management in Asian patients, taking into account Asian characteristics. Hypertension 2018;71:375-82.

PUBMED | CROSSREF

72. Arima H, Murakami Y, Lam TH, et al. Effects of prehypertension and hypertension subtype on cardiovascular disease in the Asia-Pacific Region. Hypertension 2012;59:1118-23. PUBMED | CROSSREF

73. Hoshide S, Wang JG, Park S, et al. Treatment considerations of clinical physician on hypertension management in Asia. Curr Hypertens Rev 2016;12:164-8. PUBMED | CROSSREF

74. Uzu T, Ishikawa K, Fujii T, Nakamura S, Inenaga T, Kimura G. Sodium restriction shifts circadian rhythm of blood pressure from nondipper to dipper in essential hypertension. Circulation 1997;96:1859-62. PUBMED | CROSSREF

75. Kario K, Bhatt DL, Brar S, Bakris GL. Differences in dynamic diurnal blood pressure variability between Japanese and American treatment-resistant hypertensive populations. Circ J 2017;81:1337-45. PUBMED | CROSSREF

76. Omboni S, Aristizabal D, De la Sierra A, et al. Hypertension types defined by clinic and ambulatory blood pressure in 14143 patients referred to hypertension clinics worldwide. Data from the ARTEMIS study. $J$ Hypertens 2016;34:2187-98. PUBMED | CROSSREF

77. Zhou HH, Koshakji RP, Silberstein DJ, Wilkinson GR, Wood AJ. Racial differences in drug response. Altered sensitivity to and clearance of propranolol in men of Chinese descent as compared with American whites. N Engl J Med 1989;320:565-70. PUBMED | CROSSREF

78. Kario K, Kim BK, Aoki J, et al. Renal denervation in Asia: consensus statement of the Asia Renal Denervation Consortium. Hypertension 2020;75:590-602. PUBMED | CROSSREF

79. Yang JH, Choi SH, Gwon HC. Percutaneous renal sympathetic denervation for the treatment of resistant hypertension with heart failure: first experience in Korea. J Korean Med Sci 2013;28:951-4. PUBMED | CROSSREF

80. Kim BK, Böhm M, Mahfoud F, et al. Renal denervation for treatment of uncontrolled hypertension in an Asian population: results from the Global SYMPLICITY Registry in South Korea (GSR Korea). J Hum Hypertens 2016;30:315-21. PUBMED | CROSSREF

81. Stavropoulos K, Patoulias D, Imprialos K, et al. Efficacy and safety of renal denervation for the management of arterial hypertension: a systematic review and meta-analysis of randomized, shamcontrolled, catheter-based trials. J Clin Hypertens (Greenwich) 2020;22:572-84. PUBMED | CROSSREF

82. Agasthi P, Shipman J, Arsanjani R, et al. Renal denervation for resistant hypertension in the contemporary era: a systematic review and meta-analysis. Sci Rep 2019;9:6200. PUBMED | CROSSREF

83. Cheng X, Zhang D, Luo S, Qin S. Effect of catheter-based renal denervation on uncontrolled hypertension: a systematic review and meta-analysis. Mayo Clin Proc 2019;94:1695-706. PUBMED | CROSSREF

84. Francis GS, Goldsmith SR, Levine TB, Olivari MT, Cohn JN. The neurohumoral axis in congestive heart failure. Ann Intern Med 1984;101:370-7. PUBMED | CROSSREF

85. Waagstein F, Bristow MR, Swedberg K, et al. Beneficial effects of metoprolol in idiopathic dilated cardiomyopathy. Lancet 1993;342:1441-6.

PUBMED | CROSSREF 
86. The Cardiac Insufficiency Bisoprolol Study II (CIBIS-II): a randomised trial. Lancet 1999;353:9-13. PUBMED | CROSSREF

87. Packer M, Coats AJ, Fowler MB, et al. Effect of carvedilol on survival in severe chronic heart failure. $N$ Engl JMed 2001;344:1651-8. PUBMED | CROSSREF

88. SOLVD Investigators, Yusuf S, Pitt B, Davis CE, Hood WB, Cohn JN. Effect of enalapril on survival in patients with reduced left ventricular ejection fractions and congestive heart failure. $N$ Engl J Med 1991;325:293-302. PUBMED | CROSSREF

89. Granger CB, McMurray JJ, Yusuf S, et al. Effects of candesartan in patients with chronic heart failure and reduced left-ventricular systolic function intolerant to angiotensin-converting-enzyme inhibitors: the CHARM-Alternative trial. Lancet 2003;362:772-6.

PUBMED | CROSSREF

90. Cohn JN, Tognoni G; Valsartan Heart Failure Trial Investigators. A randomized trial of the angiotensinreceptor blocker valsartan in chronic heart failure. N Engl J Med 2001;345:1667-75. PUBMED | CROSSREF

91. Brandt MC, Mahfoud F, Reda S, et al. Renal sympathetic denervation reduces left ventricular hypertrophy and improves cardiac function in patients with resistant hypertension. J Am Coll Cardiol 2012;59:901-9. PUBMED | CROSSREF

92. Davies JE, Manisty CH, Petraco R, et al. First-in-man safety evaluation of renal denervation for chronic systolic heart failure: primary outcome from REACH-Pilot study. Int J Cardiol 2013;162:189-92. PUBMED | CROSSREF

93. Patel HC, Rosen SD, Hayward C, et al. Renal denervation in heart failure with preserved ejection fraction (RDT-PEF): a randomized controlled trial. Eur J Heart Fail 2016;18:703-12. PUBMED | CROSSREF

94. Schotten U, Verheule S, Kirchhof P, Goette A. Pathophysiological mechanisms of atrial fibrillation: a translational appraisal. Physiol Rev 2011;91:265-325. PUBMED | CROSSREF

95. Pokushalov E, Romanov A, Corbucci G, et al. A randomized comparison of pulmonary vein isolation with versus without concomitant renal artery denervation in patients with refractory symptomatic atrial fibrillation and resistant hypertension. J Am Coll Cardiol 2012;60:1163-70. PUBMED | CROSSREF

96. Steinberg JS, Shabanov V, Ponomarev D, et al. Effect of renal denervation and catheter ablation vs catheter ablation alone on atrial fibrillation recurrence among patients with paroxysmal atrial fibrillation and hypertension: the ERADICATE-AF randomized clinical trial. JAMA 2020;323:248-55. PUBMED | CROSSREF

97. Sarafidis PA, Sharpe CC, Wood E, et al. Prevalence, patterns of treatment, and control of hypertension in predialysis patients with chronic kidney disease. Nephron Clin Pract 2012;120:c147-55. PUBMED | CROSSREF

98. Hering D, Mahfoud F, Walton AS, et al. Renal denervation in moderate to severe CKD. J Am Soc Nephrol 2012;23:1250-7. PUBMED | CROSSREF

99. Hering D, Marusic P, Duval J, et al. Effect of renal denervation on kidney function in patients with chronic kidney disease. Int J Cardiol 2017;232:93-7. PUBMED | CROSSREF

100. Kiuchi MG, Maia GL, de Queiroz Carreira MA, et al. Effects of renal denervation with a standard irrigated cardiac ablation catheter on blood pressure and renal function in patients with chronic kidney disease and resistant hypertension. Eur Heart J 2013;34:2114-21. PUBMED | CROSSREF

101. Scalise F, Sole A, Singh G, et al. Renal denervation in patients with end-stage renal disease and resistant hypertension on long-term haemodialysis. J Hypertens 2020;38:936-42.

PUBMED | CROSSREF 